\title{
Temperature Assessment and Plantar Inflammation
}

\author{
HARRY T. BERGTHOLDT AND PAUL W. BRAND \\ Rehabilitation Branch, U.S. Public Health Service Hospital, Carville, Louisiana, U.S.A.
}

\begin{abstract}
The rehabilitation of the healed plantar ulcer is difficult to monitor by routine methods. Monitoring of skin temperature has been found to detect the early inflammatory response of the soft tissues to the insult imposed during walking. Methods of doing this are discussed and case histories described. The human hand, though quantitatively inaccurate, can effectively detect temperature contrasts. If routine management follows the recognition of early inflammatory responses, deformity can be prevented.
\end{abstract}

\section{Introduction}

The prevention of the plantar ulcer, a common problem in Hansen's disease, is a serious and seemingly unsurmountable task. Patient education, safety procedures and adequate footwear all have been beneficial in reducing the incidence of ulceration of the insensitive foot. Ulceration continues to be a problem regardless of the standard procedures implemented. Modification of the shoe to reduce the pressures on the plantar surface to an acceptable level may be satisfactory for 500 steps, but would the soft tissue tolerate 5000 steps at the same level? It may tolerate 5000 steps, but not 5000 steps every day. Brand (1966) demonstrated that moderate levels of stress, which are acceptable for a few repetitions, may be harmful when continued for long periods of time. As the tissue becomes injured, an inflammatory response with resultant hyperemia develops and, if the irritation continues, the tissue is damaged with subsequent ulceration. Once an opening in the skin exists, infection may occur with the often seen complications.

The hyperaemia due to the inflammatory response of tissues to repeated bouts of stress can be determined by monitoring skin temperature using one of several methods: thermographic unit, liquid crystals, radiometer, thermistor and thermocouple, and the human hand. The advantages and disadvantages of the various methods are listed in Table 1. Although the human hand is not quantitatively accurate, it can be very effective in recognizing increased heat. Health workers and patients can be taught to use their hands or temperature sensitive skin effectively by palpating for "hot areas."

At the U.S.P.H.S. Hospital, Carville, Louisiana, all methods of temperature recording are available and used. This manuscript will deal primarily with thermography as a method of temperature recording, but the information derived from this method may be utilized with the other methods as well. 
TABLE 1

Temperature monitoring equipment

\begin{tabular}{|c|c|c|}
\hline & Advantages & Disadvantages \\
\hline Thermographic units & $\begin{array}{l}\text { Rapid screening } \\
\text { Accurate }\left(0.2^{\circ} \mathrm{C}\right) \\
\text { Non-contact }\end{array}$ & Cost $-\$ 30,000(?)$ \\
\hline Liquid crystals & $\begin{array}{l}\text { Screening capability } \\
\text { Inexpensive }\end{array}$ & $\begin{array}{l}\text { Contact necessary } \\
\text { Messy } \\
\text { Narrow temperature ranges }\end{array}$ \\
\hline Radiometer & $\begin{array}{l}\text { Rapid spot recording } \\
\text { Accurate }\left(0.5^{\circ}()\right. \\
\text { Non-contact }\end{array}$ & $\begin{array}{l}\text { Cost }-\$ 800.00(?) \\
\text { Poor screening capability }\end{array}$ \\
\hline $\begin{array}{l}\text { Thermistor or } \\
\text { Thermocouple }\end{array}$ & $\begin{array}{l}\text { Inexpensive (less } \$ 200) \\
\text { Accurate }\left(0.1^{\circ} \mathrm{C}\right) \\
\text { Durable } \\
\text { Small }\end{array}$ & $\begin{array}{l}\text { Slow response }(10-20 \mathrm{~s}) \\
\text { Contact necessary } \\
\text { Poor screening capabilities }\end{array}$ \\
\hline $\begin{array}{l}\text { Hand or temperature } \\
\text { sensitive skin }\end{array}$ & $\begin{array}{l}\text { Free } \\
\text { Screening capability } \\
\text { Availability anywhere }\end{array}$ & Inaccurate $\left(<2^{\circ} \mathrm{C}\right)$ \\
\hline
\end{tabular}

A thermographic unit measures the thermal (infrared) emission of energy from an object and displays it in a manner similar to a television image on a video screen. The range of temperatures is represented with a continuous grey scale with warm areas of the skin showing up as shades of white and cooler areas as darker shades. A single temperature may be electronically highlighted as a bright line. The use of two such "isotherms" allows the operator to measure the absolute temperature and the difference $(\Delta T)$ between the highlighted areas. A more detailed discussion of the application of thermography is given by Gershon-Cohen and Barnes (1964).

The surface temperature of skin varies, depending on the location. Generally, skin temperatures become lower as the distance increases from the trunk with certain exceptions. Each individual has a characteristic thermal pattern on the feet and lower legs which is symmetrical if no pathology is present. Differences of greater than $1^{\circ} \mathrm{C}$ are considered to be significant and should be evaluated. With peripheral nerve involvement, abnormal surface temperature patterns may become evident. They show uniform patterns, however, in individuals unless pathological changes occur.

Levan et al. (1969) used thermography to determine the temperature of lepromatous skin lesions and found that large hypopigmented macules were 0.3 to $2^{\circ} \mathrm{C}$ warmer than the surrounding tissue. They used blood flow studies to confirm that the elevated temperature they found reflected an increase in blood flow. They concluded after testing the patients' local sensitivity to norepinephrine that the hyperaemia was due to autonomic degeneration rather than to an inflammatory response.

Enna and Bergtholdt (1973) reported thermography showed that nerve paralysis found in leprosy patients' hands created unique but consistent thermal patterns. 
Harris and Brand (1966) found local warmth to be one of the earliest signs of tarsal disintegration that oceurs in the anaesthetic foot, and they used it as a guide to identify active disintegration in anaesthetic feet. Brand et al. (1970) studied the temperature patterns of leprosy patients after minor injuries and trauma, and found that anaesthetic limbs often had localized warm areas at the point of stress. They felt it worthwhile to pursue this area of investigation.

After several years of experimentation and observation in thermograms taken of normal feet under stress and of leprosy patients feet, including feet with complete anaesthesia and often gross deformity and paralysis, it has become obvious that warmth can be an important sign to monitor. Several case studies are presented to demonstrate the findings which have proved to be useful.

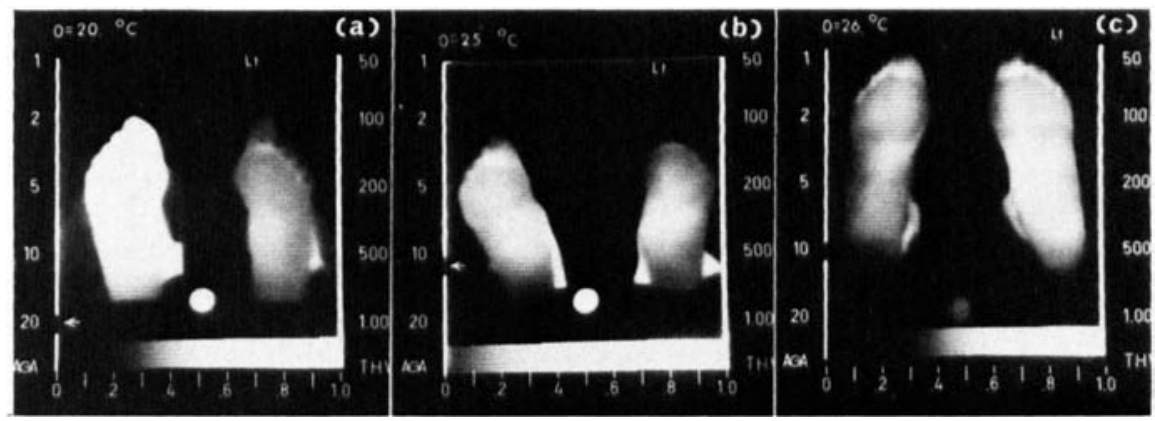

Fig. 1. Thermograms of plantar surface of insensitive feet following blistering of right matatarsal heads. (a) Thermogram 7 days following injury. (b) Thermogram after 6 days of immobilization. (c) Thermogram after 7 days of walking.

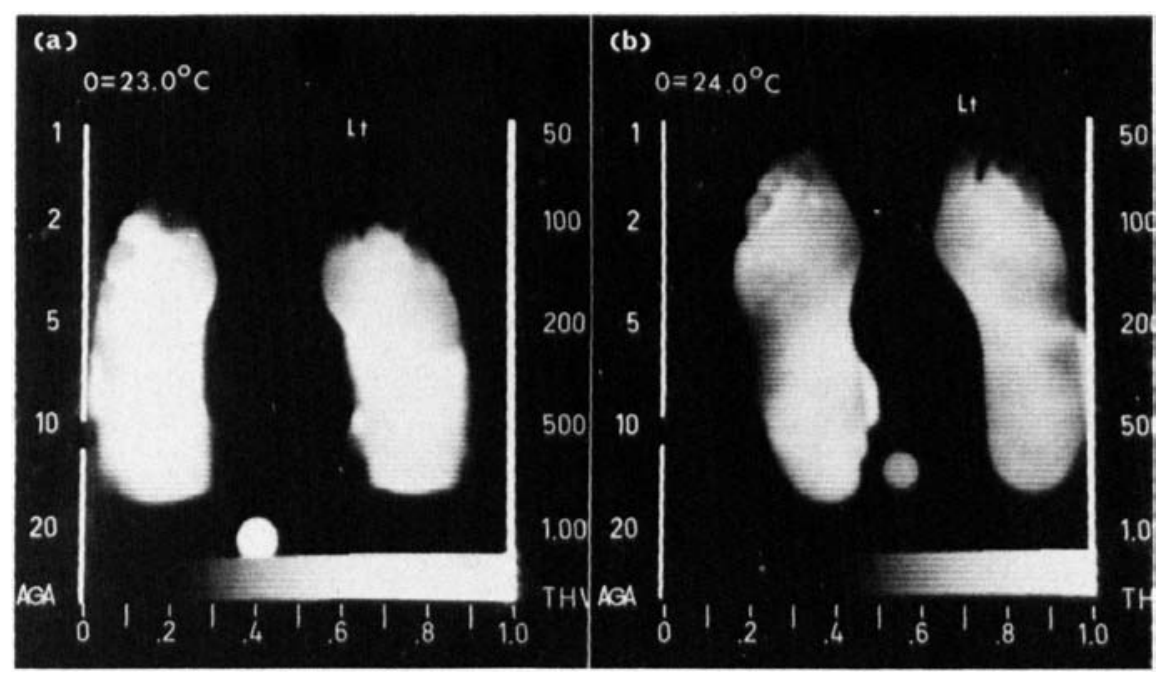

Fig. 2. Thermograms of plantar surface of insensitive feet. (a) Ten days after treatment started. (b) Forty-nine days after treatment started, after one month of routine walking. 


\section{Case Studies}

\section{METHOD}

The feet were exposed in the environmentally controlled room at a temperature of $21^{\circ}-22^{\circ}$ ( for 10 to $15 \mathrm{~min}$ to allow the normal skin temperature to equilibrate with the room air. This produced a surface temperature difference between the normal and inflamed tissue. The AGA 680 Thermovision* was used throughout the study. The thermograms were recorded on Polaroid film in black and white, and $35 \mathrm{~mm}$ slides were made from the color monitor.

Case Study 1. A 42-year-old patient with a diagnosis of inactive dimorphous leprosy for the last year had total anaesthesia of the feet. She had been walking a great deal in small high heel shoes and suffered blisters over the right metatarsal heads. Minimal drainage occurred, but no bacteria were found on culture. Seven (lays later, no improvement was noted. At this time a thermogram (Fig. 1) showed the entire plantar surface of the right foot was warm and $12^{\circ} \mathrm{C}$ warmer than the contralateral site. The warmest region $\left(37^{\circ} \mathrm{C}\right)$ was over the second, third and fourth metatarsal heads. The leg was placed in a plaster total contact cast for a period of 6 days. The increased warmth present had decreased with a contralateral temperature difference of less than $1^{\circ} \mathrm{C}$.

The patient's shoes were modified and instructions were given concerning the necessity of proper shoe wear. One week later the thermogram shows the involved region had a near normal thermal pattern (Fig. 1).

Case Study 2. A 54-year-old patient with inactive lepromatous leprosy and

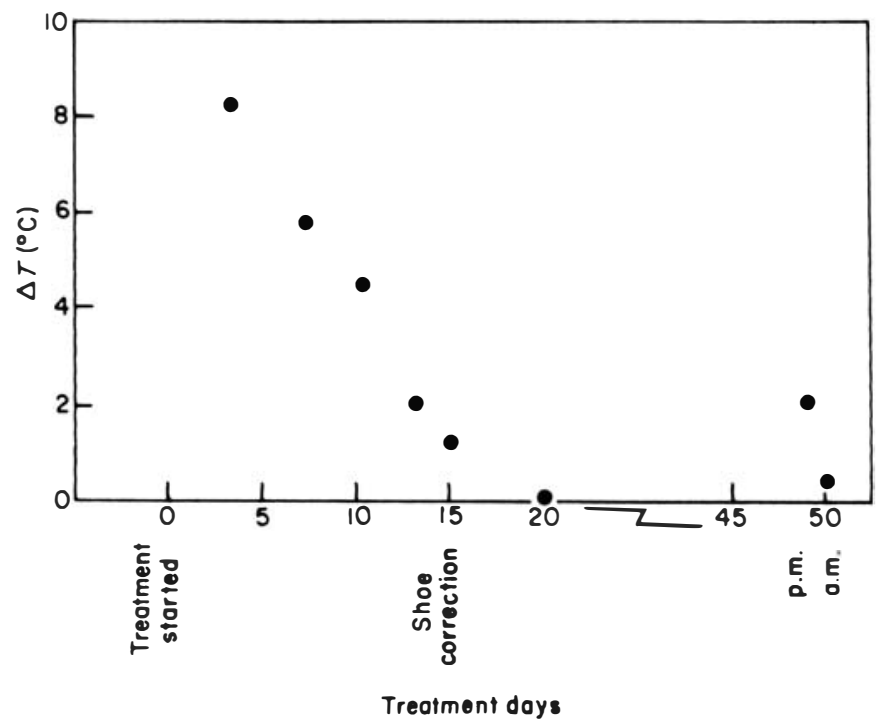

Fig. 3. Table showing the temperature difference between right third toe and left third toe $(\Delta \mathrm{T})$ during course of treatment.

* AGA Corporation, 500 County Avenue, Secaucus, New Jersey 07094. Company names are mentioned in this paper for the purpose of identification, and does not imply endorsement by the U.S. Public Health Service. 


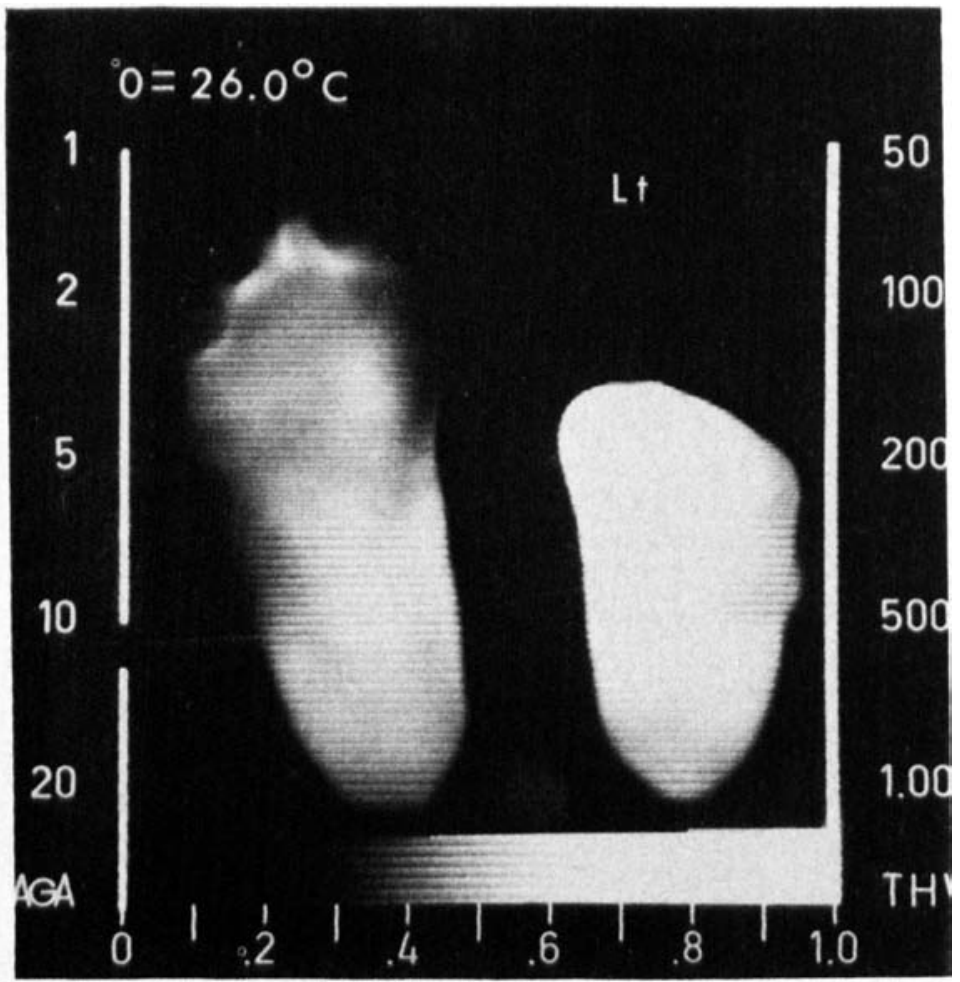

Fig. 4. Thermogram of plantar surface of insensitive feet (left transmetatarsal amputation).

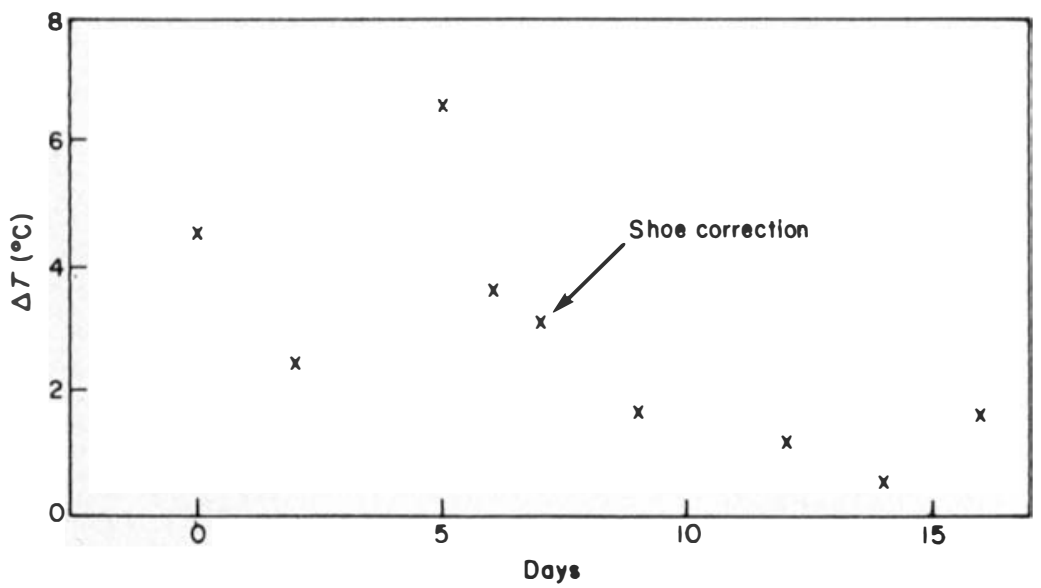

Fig. 5. Table showing the $\Delta \mathrm{T}$ for end of left first metatarsal vs. contralateral site tollowing observation of hematoma. 
total anaesthesia of the feet noticed the right third toe tit) had a callus present with a small amount of clear drainage. The treatment prescribed included soaking with an antiseptic soap, elevation and an appropriate antihiotic. Periodic thermograms were taken of the feet starting 3 days later. The involved toc wals found to be highly intlamed, heing $8.2^{\circ}$ C' warmer than the eontralateral toe. The entire forefoot on the plantar surface was warm with the warmth present over the entire dorsal surface as well. During the course of treatment, as the inflammation was subsiding, the warmth became localized and the temperature difference between the right third toe and the contralateral site decreased (figs 2 and 3 ). Fifteen days later, the toe appeared healed and its temperature was the same as the contralateral toe. The patient was sent to the shoe shop for shoe assessment and necessary shoe modifications. The patient began a progressive ambulation routine for 5 (lays, and was then released to return to work. One month later, a thermogram was taken of the patient's feet following a day of woik (Fig. 2). ()nly a minimal degree of warmth was noted, which returned to a normal thermal pattern the following morning after a night's rest.

Case Study 3. A 68-year-old patient with inactive lepromatous lenrosy had a transmetatarsal amputation of the left foot 10 years ago. The patient reported to

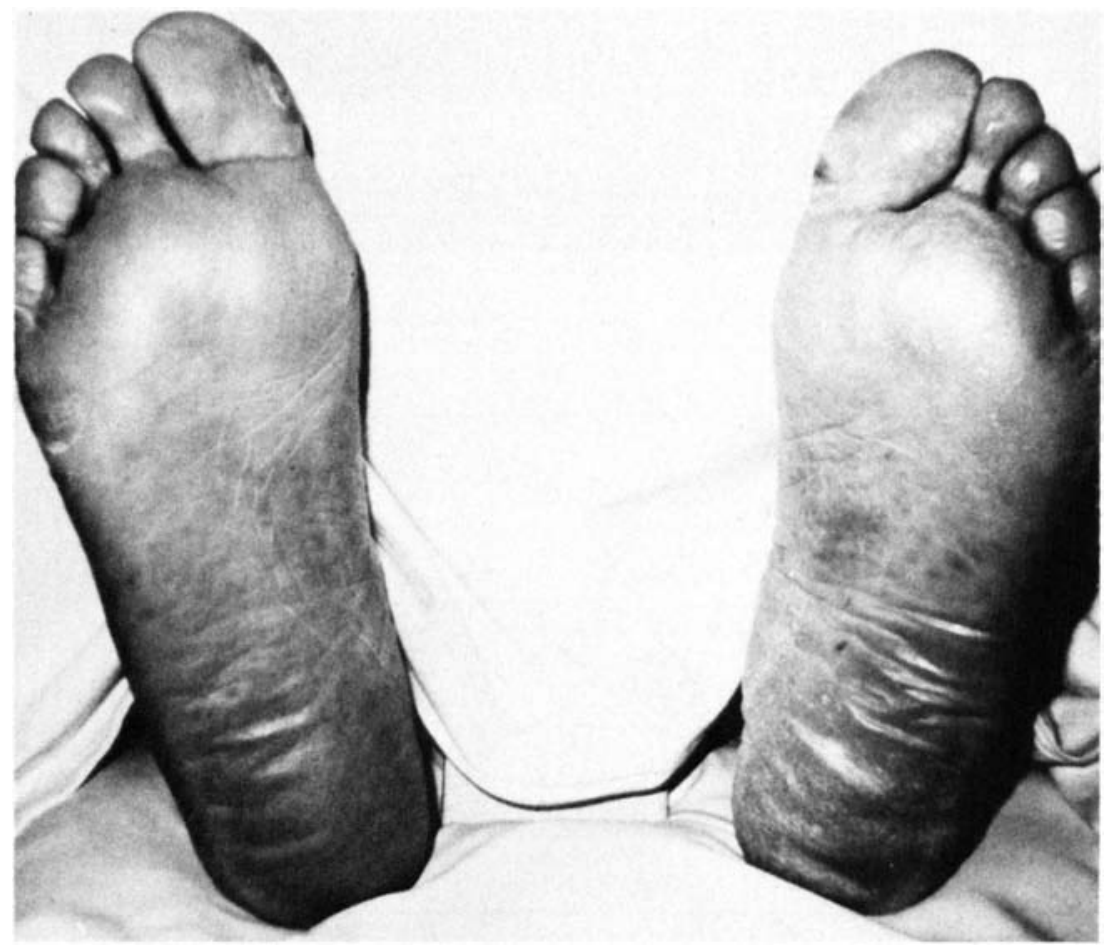

Fig. 6. Photograph of insensitive feet with callosities on right great toe, first, second, fifth metatarsal heads; and left great toe, third and fif th metatarsal heads. 

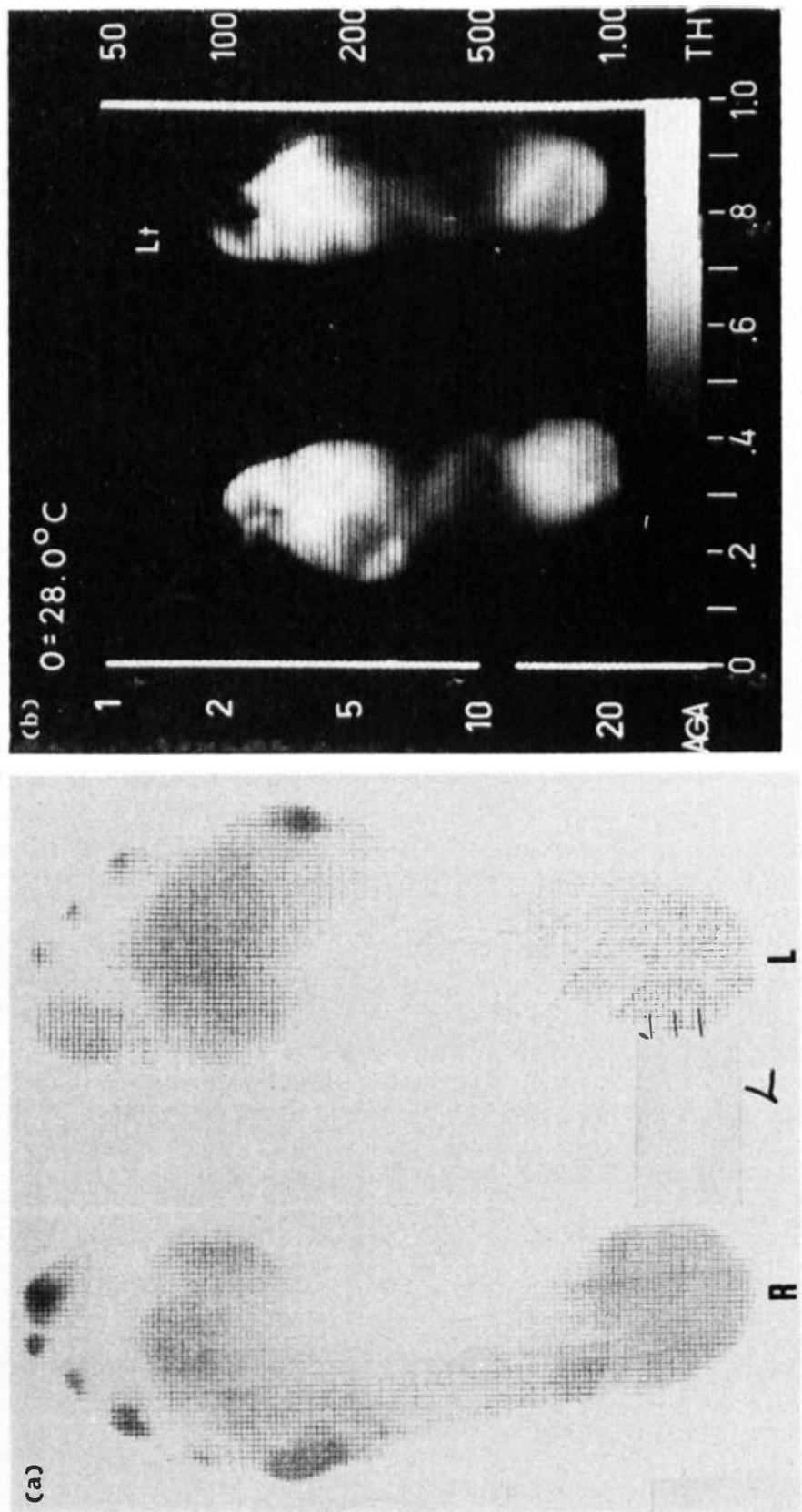
the shoe shop with a large callus and a blood blister under the distal aspect of the left first metatarsal. A thermogram (Fig. 4) showed the entire left foot was warm, with the warmest aspect at the end of the first metatarsal, which was $4.4^{\circ} \mathrm{C}$ warmer than the contralateral site. Soaking, trimming of the callus, and shoe evaluation was prescribed. The condition of the injury become worse. No opening or drainage was noted however, and the $\Delta \mathrm{T}$ increased to $6.5^{\circ} \mathrm{C}$ (Fig. 5) by the fifth day of observation. Further shoe pressure evaluations showed the injured area was rubbing the distal-medial edge of the moulded insole. A further shoe modification apparently stopped the excessive repetitive stress to the area, as can be seen by the improvement of the $\Delta T$ (Fig. 5), and then by the clinical improvement. By the 14th and 16th days, the foot had cooled to a near normal level, and the wound appeared to be healed.

Case Study 4. A 43-year-old patient with active lepromatous leprosy had practically complete anaesthesia over the entire body. The patient had multiple trimmed callosities over the plantar surface of the feet (Fig. 6). Pressure assessment, using the Harris Foot Mat, demonstrated the areas with heavy callus were the areas under greatest pressure during standing and walking (Fig. 7). A thermogram taken of the plantar surface of the feet showed the areas under greatest pressure were the warmest areas of the feet (Fig. 8). These hot areas suggested that the weight bearing surfaces of the feet were inflamed from walking, and if the stress due to walking increased, breakdown and ulceration would follow.

\section{Discussion}

Rehabilitation of the healed ulcer is difficult to monitor by routine methods. Low levels of repetitive walking need to be increased as the healed area toughens, but too much walking is harmful. Current methods of evaluation do not indicate the response of the foot to the toughening process. Monitoring of skin temperature has been found to be a practical method as a guide for a progressive rehabilitation programme by evaluating the tissue's response to the gradual increase in the walking programme.

The insensitive and paralytic foot is best managed before scar and deformity from ulceration reduce the stress threshold of the weight bearing surfaces of the foot. Each plantar ulcer will reduce the patient's foot tolerance to the repetitive stress imposed during walking. Prevention of the ulcer, therefore, should be paramount in the management of insensitive feet. Temperature monitoring has been found to detect the early inflammatory response of the soft tissue to the insult imposed during walking. If routine management is provided upon recognizing the early inflammatory responses, deformity can be averted.

\section{References}

Brand, P. W. (1966). Insensitive feet. A practical handbook on foot problems in leprosy. No. 3. London: Leprosy Mission.

Brand, P. W. et al. (1970). Sensory denervation. A study of its cause and its prevention in leprosy and of the management of insensitive limbs. SRS Project No. RC-40-M, Final Report, U.S. Public Health Service Hospital, Carville, Louisiana.

Enna, C. D. and Bergtholdt, H. T. (1973). Temperature studies of the hand and its claw deformities due to peripheral nerve paralysis in leprosy. The Hand 5, 10 .

Gershon-Cohen, J. (1967). Medical thermography. Scient. Am. 216, 94. 
Gershon-Cohen, J. and Barnes, R. B. (1964). Thermography and its clinical applications. Ann. N.Y. Acad. Sci. 121,1 .

Harris, J. R. and Brand, P. W. (1966). Patterns of disintegration of the tarsus in the anaesthetic foot. J. Bone Jt Surg. 48B, 4.

Lautenbach, E. F. (i. (1971). The assessment of progress in osteomyleitis. S. Afr. J. Surg. 9, 201.

Levan, N. E. et al. (1969). Temperature and blood flow in macules of lepromatous leprosy. Int. J. Lepr. 37, 249.

Ryan, J. (1969). Thermography. Aust. Radiol. 13, 23.

Skinsnes, O. K. et al. (1972). Pathogenesis of extremity deformity in leprosy. A pathological study on large sections of amputated extremities in relation to radiological appearance. Int. J. Lepr. 40, 375.

Verhonick, P. J. et al. (1972). Thermography in the study of decubitus ulcers. Preliminary report. Nursing Research 21, 233. 